\title{
SuperDARN radar HF propagation and absorption response to the substorm expansion phase
}

\author{
J. K. Gauld ${ }^{1}$, T. K. Yeoman ${ }^{1}$, J. A. Davies ${ }^{1}$, S. E. Milan ${ }^{1}$, and F. Honary ${ }^{2}$ \\ ${ }^{1}$ Department of Physics and Astronomy, University of Leicester, University Road, Leicester, LE1 7RH, UK \\ ${ }^{2}$ Department of Communication Systems, University of Lancaster, Bailrigg, Lancaster, LA1 4YR, UK
}

Received: 30 November 2001 - Revised: 21 March 2002 - Accepted: 27 March 2002

\begin{abstract}
Coherent scatter HF ionospheric radar systems such as SuperDARN offer a powerful experimental technique for the investigation of the magnetospheric substorm. However, a common signature in the early expansion phase is a loss of HF backscatter, which has limited the utility of the radar systems in substorm research. Such data loss has generally been attributed to either HF absorption in the Dregion ionosphere, or the consequence of regions of very low ionospheric electric field. Here observations from a well-instrumented isolated substorm which resulted in such a characteristic HF radar data loss are examined to explore the impact of the substorm expansion phase on the HF radar system. The radar response from the SuperDARN Hankasalmi system is interpreted in the context of data from the EISCAT incoherent scatter radar systems and the IRIS Riometer at Kilpisjarvi, along with calculations of HF absorption for both IRIS and Hankasalmi and ray-tracing simulations. Such a study offers an explanation of the physical mechanisms behind the HF radar data loss phenomenon. It is found that, at least for the case study presented, the major cause of data loss is not $\mathrm{HF}$ absorption, but changes in HF propagation conditions. These result in the loss of many propagation paths for radar backscatter, but also the creation of some new, viable propagation paths. The implications for the use of the characteristics of the data loss as a diagnostic of the substorm process, HF communications channels, and possible radar operational strategies which might mitigate the level of HF radar data loss, are discussed.
\end{abstract}

Key words. Ionosphere (ionosphere-magnetosphere interactions). Magnetospheric physics (storms and substorms). Radio science (radio wave propagation)

\section{Introduction}

Ionospheric radar systems are a powerful diagnostic of the spatial and temporal evolution of the ionospheric electro-

Correspondence to: T. K. Yeoman

(tim.yeoman@ion.le.ac.uk) jets during the substorm expansion phase. These are known to have a highly time-dependent electric and magnetic field and conductivity structure, as a consequence of the electric field and particle precipitation imposed on the nightside ionosphere by the Earth's magnetotail, and the resulting current systems. These ionospheric electric field and conductivity changes combine to produce the characteristic ground magnetic perturbations during the substorm expansion phase. VHF coherent scatter radars were first used to study the spatial structure of the substorm ionospheric electric fields (Baumjohann et al., 1981; Inhester et al., 1981; Opgenoorth et al., 1989) and suggested a region of low electric field within the dynamic structure of the substorm electrojets. The extensive fields-of-view of high-frequency (HF) coherent scatter ionospheric radars make them excellent instruments for the investigation of the larger scale spatial and temporal development of the ionospheric electric fields (e.g. Morelli et al., 1995; Lewis et al., 1997; Shand et al., 1998). This is especially true for the SuperDARN network, which offers an extensive network of such radars in the Northern and Southern Hemispheres. One of the main advantages of HF radars over VHF radars is their improved ability to investigate the high conductivity, low electric field region of the ionospheric location of substorm onset, where a drop out in E-region backscatter, indicative of low flow velocity (a consequence of VHF E-region radar instrumental threshold effects, see, e.g. Robinson (1986)), has hampered previous VHF radar studies (e.g. Baumjohann et al., 1981; Inhester et al., 1981). During the substorm expansion phase, such HF coherent radars have observed dynamic convection features, which correspond to azimuthally propagating fieldaligned current systems, which may be related to reconnection and bursty bulk flows in the magnetotail (Yeoman and Lühr, 1997; Yeoman et al., 1998). Localized electrojet features in which ionospheric flows were suppressed to values as low as $50 \mathrm{~m} / \mathrm{s}$ and accelerated up to values as high as $1 \mathrm{~km} / \mathrm{s}$ within a few minutes have also been observed at the western edge of the substorm-disturbed electrojet, accompanied by conductance variations between 20 and $100 \mathrm{~S}$ (Morelli et al., 1995). However, substorm-associated HF absorption has, in 
the past, limited the use of HF radar systems. A common signature in the early expansion phase is a loss of HF backscatter (e.g. Yeoman and Lühr, 1997; Yeoman et al., 2000; Lester et al., 2001). Such data loss has generally been attributed to either absorption of the HF radar signal in the D-region ionosphere (Milan et al., 1996) or data loss due to ionospheric irregularity suppression in regions of very low electric field (Milan et al., 1999). Here an interval of substorm activity, which features such a characteristic HF radar data loss, is examined with a number of observational techniques to explore the impact of the substorm expansion phase on the HF radar system. The SuperDARN Hankasalmi radar response is characterized and interpreted in the context of the additional information provided by the EISCAT incoherent scatter radar systems and the IRIS Riometer at Kilpisjarvi. These data are supplemented by calculations of HF absorption and raytracing simulations. Such a study provides a full explanation of the physical mechanisms which result in the loss of HF radar backscatter during substorms. The study also suggests that the edge of the data loss itself may be used as a diagnostic of the substorm process. Investigation of the HF radar angle-of-arrival information could also lead to radar operational strategies, such as frequency management, which will mitigate the level of HF radar data loss.

\section{Instrumentation}

The ionospheric convection velocities in this study are provided by three ionospheric radar systems, the Hankasalmi radar of the SuperDARN chain of coherent scatter HF radars (Greenwald et al., 1995), the EISCAT VHF radar at Troms $\varnothing$ (e.g. Rishbeth and Williams, 1985) and the EISCAT Svalbard radar (ESR), located at Longyearbyen (e.g. Wannberg et al., 1997). The fields-of-view of these systems during the interval under study are illustrated in Fig. 1.

The SuperDARN radars form 16 beams of azimuthal separation $3.24^{\circ}$. Each beam is gated into 75 range bins, each of length $45 \mathrm{~km}$ in standard operations. During standard operations the dwell time for each beam is $7 \mathrm{~s}$, giving a full 16 beam scan, covering $52^{\circ}$ in azimuth and over $3000 \mathrm{~km}$ in range (an area of over $4 \times 10^{6} \mathrm{~km}^{2}$ ), every $2 \mathrm{~min}$. For the interval presented here, Hankasalmi was operating in a nonstandard scan mode in which the integration time for each beam was reduced to $2 \mathrm{~s}$. This reduced integration time lowers the radar data signal-to-noise ratio slightly. The data presented are thresholded as normal at $0 \mathrm{~dB}$; thus, the reduced integration period reduces the data coverage, as low returned powers will be lost. In the auroral region, where powerful HF scatter is commonly observed, this has little overall effect on the data coverage. In addition to reduced integration periods, in the scan employed here, rather than the usual anticlockwise sweep through beams $15,14,13, \ldots, 0$, the Hankasalmi radar scanned through the sequence $15,9,14,9,13,9, \ldots, 1$, 9, 0, 9. This allows for the construction of full 16-beam scans at an enhanced temporal resolution of $64 \mathrm{~s}$, in addition to the provision of very high time resolution ( $4 \mathrm{~s})$ data along a single look direction (beam 9, a beam which approximately overlays the main meridional chain of the IMAGE array and the location of the ESR).

During the interval of interest, the EISCAT VHF and ESR radar systems were running the UK special programme SPUK-CSUB. This programme was run over 4 four-hour intervals, commencing at 21:00 UT on 20,21, 22 and $23 \mathrm{Au}-$ gust 1998. The ESR was, during SP-UK-CSUB, directed southward, with a geographic azimuth of $161.6^{\circ}$ and an elevation of $31.0^{\circ}$. This pointing direction allows for the ESR beam to be aligned in azimuth along beam 9 of the Hankasalmi radar field-of-view. The ESR was transmitting the GUP0 radar code, a multi-frequency long pulse. Received signals were integrated over $10 \mathrm{~s}$ and the data subsequently analyzed at a temporal resolution of $60 \mathrm{~s}$. Analysis of ESR data is such that the user can vary the range resolution, in this case with gating of $12 \mathrm{~km}$ below a range of $330 \mathrm{~km}$, which corresponds to an altitude of around $175 \mathrm{~km}, 36 \mathrm{~km}$ range gates from 330 to $690 \mathrm{~km}$ and $72 \mathrm{~km}$ range gates above $690 \mathrm{~km}$ range; ESR observations span the altitude range from 110 to $500 \mathrm{~km}$.

In SP-UK-CSUB, the EISCAT VHF radar operated in a split beam mode with one beam (beam 2) directed along the boresight which corresponds to a geographic azimuth of $359.5^{\circ}$ and the other (beam 1) phased $14.5^{\circ}$ west to an azimuth of $345.0^{\circ}$; both beams are at an elevation of $30^{\circ}$. In SP-UK-CSUB, which is identical to the VHF common programme CP-4, long pulse and power profile codes are transmitted. The long pulse provides observations on each beam over 20 gates of range resolution $65.3 \mathrm{~km}$, with the first gate centered at a range of $533.0 \mathrm{~km}$; this corresponds to an altitude coverage from around $280 \mathrm{~km}$ to over $1000 \mathrm{~km}$. The power profile pulse scheme yields returned power measurements at a range resolution of $4.5 \mathrm{~km}$ over 83 gates from $85 \mathrm{~km}$ to $285 \mathrm{~km}$ altitude. Like those from Svalbard, VHF observations were analyzed at 1-min temporal resolution. Beam 1 of the VHF radar is aligned in azimuth roughly along beams 6 and 7 of the Hankasalmi radar, whereas beam 2 crosses beams $7-10$ of the Hankasalmi radar.

Standard analysis of the long pulse signal from both the Svalbard and VHF radars provide estimates along each beam of both ion and electron temperature, electron density and ion velocity. The VHF power profile yields estimates of electron density in the lower ionosphere. Estimates of the Hall and Pedersen conductance can be derived from the VHF power profile measurements with the incorporation of appropriate input from the MSIS-90 thermospheric model and the IGRF model of the geomagnetic field.

The Imaging Riometer for Ionospheric Studies (IRIS, Browne et al., 1995), is located at Kilpisjarvi in northern Finland. The relationship between the field-of-view of IRIS and the ionospheric radars is displayed in Fig. 1. The system samples the level of background cosmic radio noise at $38.2 \mathrm{MHz}$, which shows a predictable diurnal power variation; any anomalies in this received power result from changes in HF absorption in the D-region ionosphere. Beam formation is carried out by an assembly of Butler matrices, 


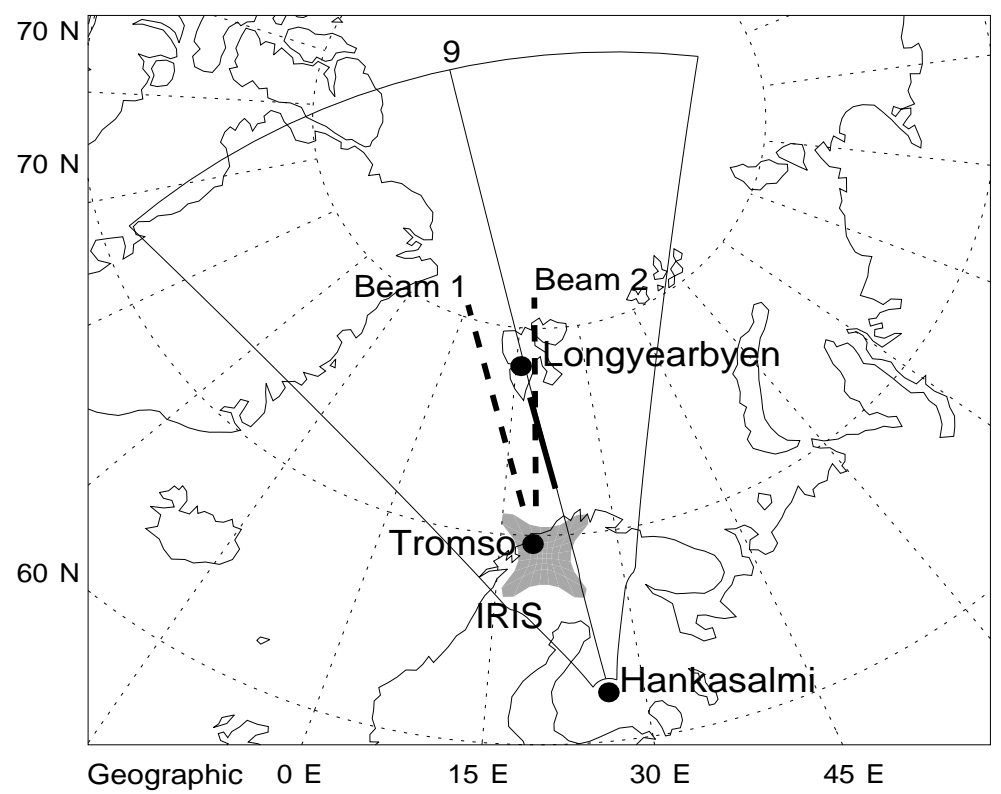

Fig. 1. The instrumentation used in the study. The field-of-view of the Hankasalmi radar is shown, with beam 9 marked explicitly with a line. The EISCAT VHF and ESR beam positions for the SP-UK-CSUB experiment are marked with heavy lines, and the IRIS riometer field-of-view is indicated by a shaded region.

the phasing resulting in 49 narrow beams, of width between $13^{\circ}$ and $16^{\circ}$. The beam intersections (Fig. 1) are shown at $90 \mathrm{~km}$, since a large proportion of the total absorption normally occurs at around this altitude. The absorption is calculated by subtracting the received power from a corresponding quiet time power curve, and then multiplying this figure by the cosine of the zenith angle of the beam. The absorption values attributed to the beams then represent the absorption which would have occurred if the beam passed vertically through the absorbing layer. This data set is supplemented here by data from ground-based fluxgate magnetometers, provided by stations from the International Monitor for Auroral Geomagnetic Effects, (IMAGE) (Lühr, 1994). The IMAGE array has $10 \mathrm{~s}$ sampling for the interval under consideration here.

\section{Observations}

The ionospheric electric and ground magnetic fields of the substorm under study here have been presented in detail by Yeoman et al. (2000) and the reader is referred to that paper for a fuller discussion of the interval. A brief outline of the pertinent features is given here. Prior to 20:25 UT on 21 August 1998, the IMF, as measured by Wind, had been northward for $20 \mathrm{~h}$, and the IMF $B_{y}$ component had been positive for $4 \mathrm{~h}$. At 20:25 UT ( $\sim 20: 58$ UT when the features are propagated to the magnetopause), both the $B_{y}$ and $B_{z}$ components abruptly switched polarity, turning negative. The IMF remained in this configuration until 22:38 UT ( $\sim 23: 11$ UT at the magnetopause), when the IMF $B_{z}$ component magnitude reduced to near zero, although the IMF
$B_{y}$ component did have a brief excursion to positive values at 21:18 UT (21:51 at the magnetopause). Some time after the IMF $B_{z}$ southward turning, at 21:40 UT, the Hankasalmi HF radar backscatter exhibited substorm growth phase signatures; namely an equatorward motion of the radar backscatter (Lewis et al., 1998; Yeoman et al., 1999). This is illustrated in Fig. 2a, which presents a latitude-time plot of the line-ofsight ionospheric velocities from Hankasalmi beam 9.

Magnetically quiet conditions apply up to 22:50 UT, when a clear mid-latitude Pi2 pulsation, indicating the substorm expansion phase onset is observed across the IMAGE array (the PEL station is illustrated in Fig. 2c), with a further Pi2 burst starting at 23:05 UT, which can be seen as a phase skip in the filtered PEL data, and is accompanied by $Y$ component fluctuations across the IMAGE chain (see Yeoman et al., 2000). The Pi2 onset and intensification are marked on Fig. 2 with solid vertical lines. The onset of the first Pi2 burst coincides with a strong negative bay (up to $300 \mathrm{nT}$ ) in the $X$ component auroral magnetograms (again, the PEL data is illustrated in Fig. 2b), indicating a substorm-enhanced westward electrojet. At this time, dynamic substorm-associated electric fields strongly modulate the line-of-sight velocities observed in Fig. 2a. The IRIS riometer (Fig. 2d presents a Keogram of the data from IRIS along a longitude of $20^{\circ}$ ) measures a slight increase in absorption at 22:50 UT at $66^{\circ}$ latitude, coincident with the first $\mathrm{Pi} 2$, and stronger, but still modest, increases in absorption at 22:56 and 23:03 UT. The main features of interest here are the two intervals of data loss apparent in the radar data at latitudes of $69^{\circ}-74^{\circ}$ (Altitude Adjusted Corrected Geomagnetic (AACGM) magnetic coordinates, Baker and Wing, 1989) at 22:59-23:02 UT and 23:07-23:21 UT, respectively. The two intervals of HF radar 


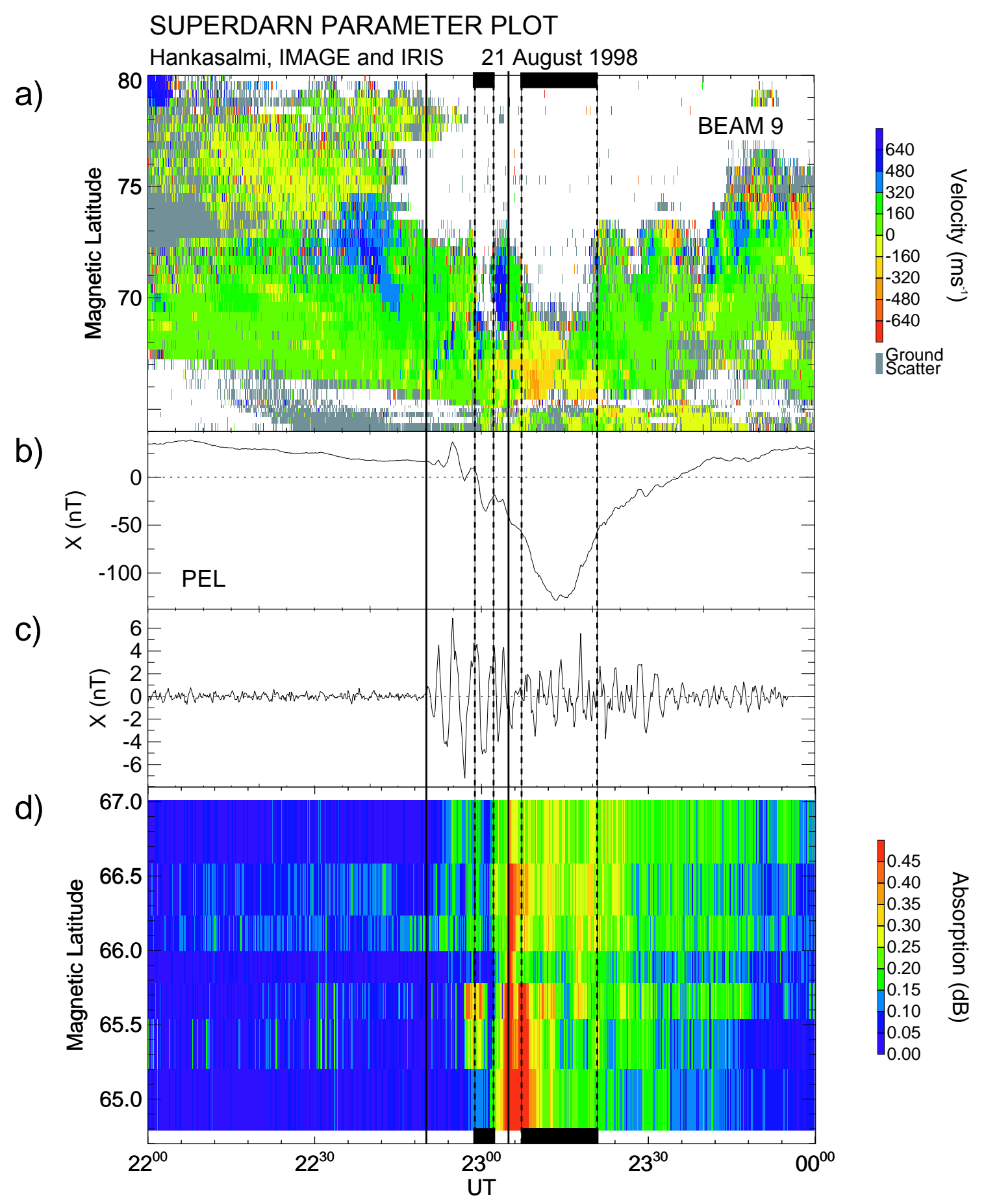

Fig. 2. Radar, magnetometer and riometer data for the isolated substorm under study. Pi2 onset times are marked with vertical solid lines and the intervals of HF radar data loss with vertical dashed lines. (a) Hankasalmi beam 9 line-of-sight velocity data from 22:00-24:00 UT, as a function of magnetic latitude, (b) unfiltered $X$ (geographic north) component magnetogram from the PEL station of the IMAGE array, over the same time interval, (c) as panel b, but with a 200-20 s band-pass filter applied, in order to illustrate the Pi2 pulsation activity associated with the substorm expansion phase onset at 22:50 UT, (d) a keogram of IRIS absorption measurements from $20^{\circ}$ longitude.

data loss are marked on Fig. 2 with dashed vertical lines.

The intervals of HF radar data loss are examined in more detail in Fig. 3. The three rows of this figure present spatial information of the HF radar backscatter power, ionospheric line-of-sight velocity and absorption measured by the IRIS system, respectively. The four columns present data from times representative of four key intervals during the substorm sequence: before the substorm expansion phase on- 


\section{Hankasalmi and IRIS Riometer Power, velocity and Absorption}
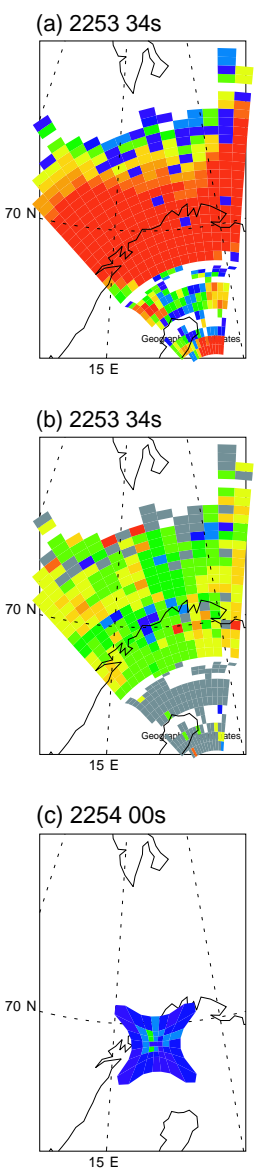
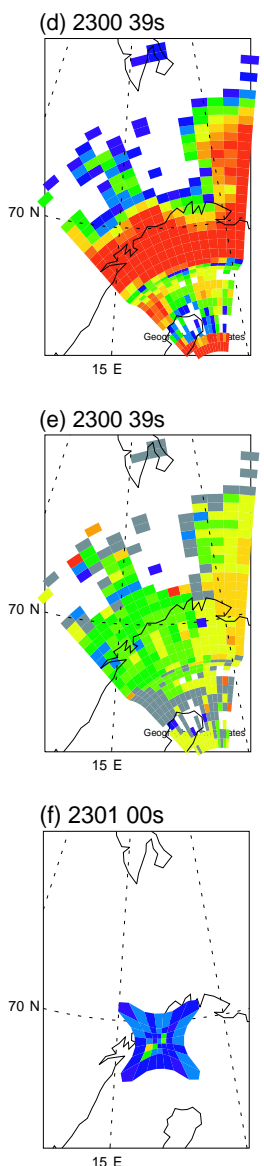
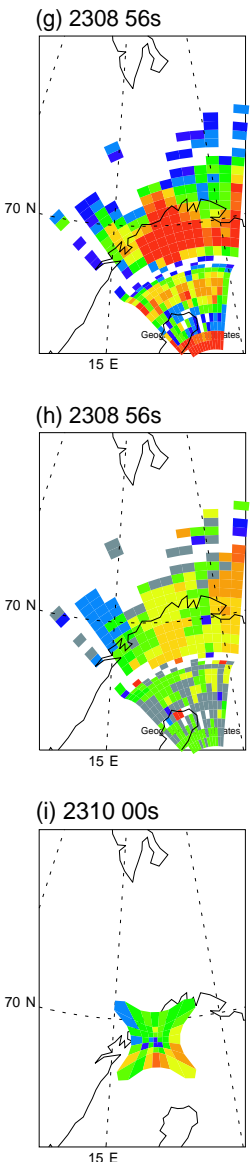

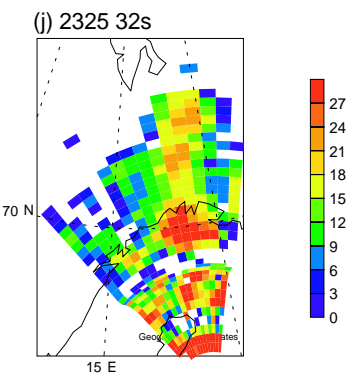

ํㅜㄹ
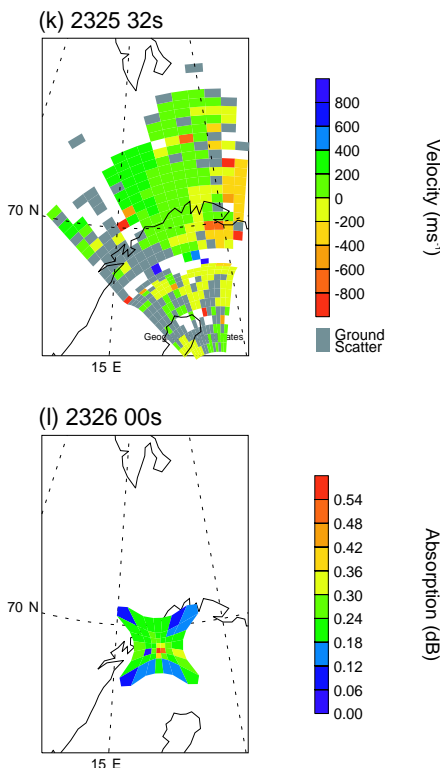

Fig. 3. Spatial distribution, in geographic coordinates, of the Hankasalmi backscatter power (top row), Hankasalmi line-of-sight velocity (middle row) and IRIS absorption (bottom row) during the substorm. The first column presents a time prior to the radar signal loss, the middle two columns present data during the signal loss period, and the final column shows the data after the radar signal has recovered.

set, during the initial period of HF radar data loss, during the second period of HF radar data loss and later on in the expansion phase. Prior to the data loss, strong radar backscatter returns are measured, and a reasonably uniform velocity field is observed, while IRIS measures very low absorption (Figs. 3a-c). In the second column, a localized region of depleted radar power is observed, along with a more structured velocity field (Figs. 3d and e). A modest increase in absorption is recorded by IRIS in Fig. 3f. In column three, a more spatially extensive region of HF radar data loss is observed (Fig. 3g). At this time the absorption measured by IRIS has significantly increased, reaching $\sim 0.5 \mathrm{~dB}$, and this enhanced absorption covers almost the entire IRIS field-of-view, although it is strongest in the southeast (Fig. 3i). Finally, in the last column, the HF radar data coverage starts to recover to values similar to Fig. 3a and the IRIS absorption reduces.

A further indication of the changing ionospheric conditions during the substorm interval may be obtained from the EISCAT system. Figure 4 presents Hankasalmi backscatter power data from beam 9, along with EISCAT estimated electron density from the VHF power profile data from beam 2 , the beam most closely aligned with beam 9 . The Pi2 onset times are marked with vertical solid lines and the intervals of HF radar data loss with vertical dashed lines, as in Fig. 2. The time of the onset of the substorm expansion phase was at 22:50 UT, as deduced from the mid-latitude $\mathrm{Pi} 2$ data. The first impact of the onset at EISCAT is clearly indicated by the increased electron density, which occurs slightly later at 22:55 UT, when a brief enhancement is observed over altitudes ranging from $95-200 \mathrm{~km}$, before the enhanced electron density retreats to higher altitudes. The increased electron density, however, extends consistently to altitudes below $95 \mathrm{~km}$ only after 23:04 UT (these altitudes correspond to magnetic latitudes of $68^{\circ}-70^{\circ}$ ). This is co-incident (within the resolution of the data) with the second mid-latitude Pi2, and it is at this time when the second HF radar data loss interval starts at the highest latitudes $\left(73^{\circ}\right)$, expanding to a latitude of $70^{\circ}$ by $23: 07 \mathrm{UT}$. 


\section{CUTLASS Power / VHF Beam 2 Power Profile}

\section{August 1998}

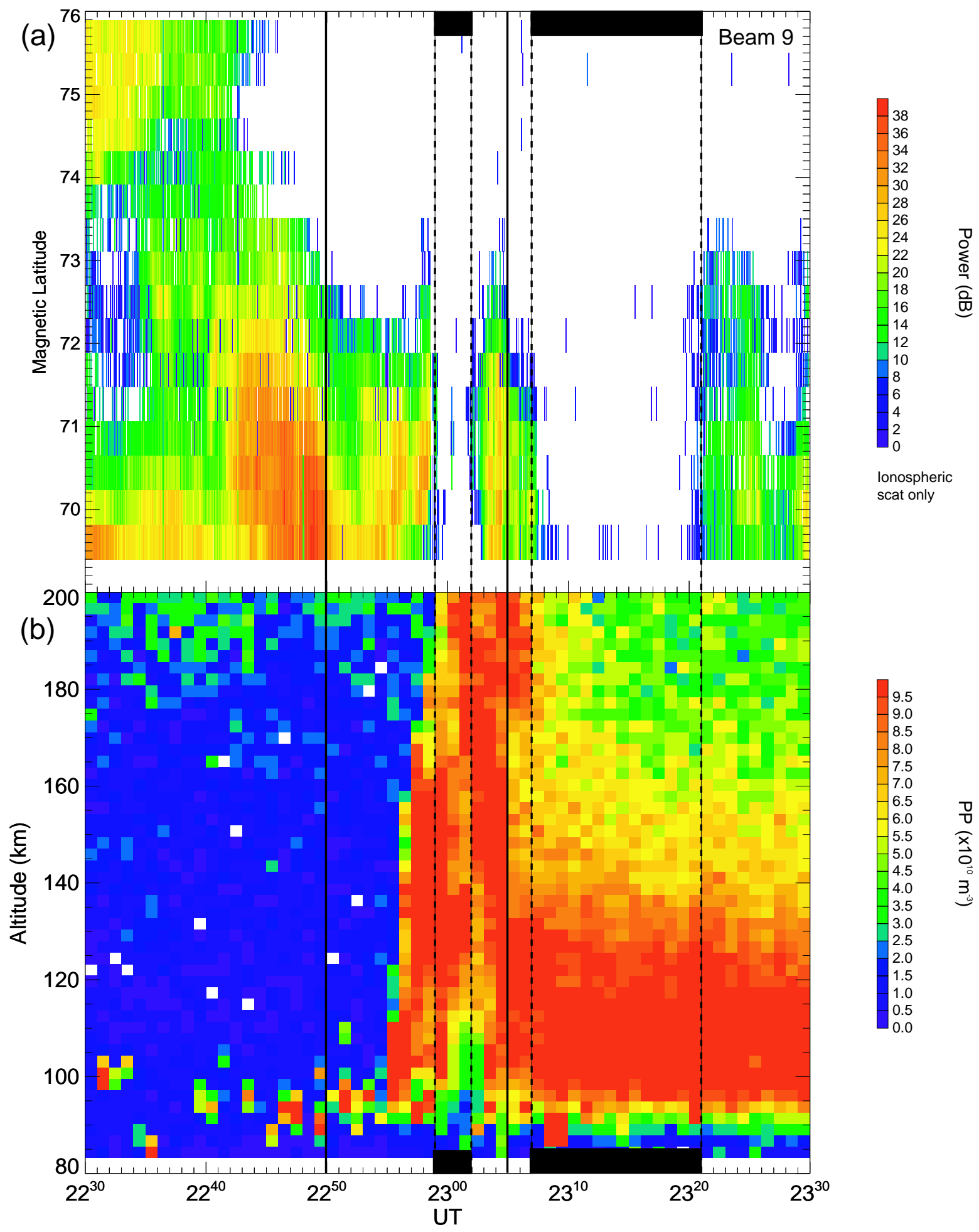

Fig. 4. (a) Hankasalmi backscatter power, as a function of magnetic latitude, for the interval 22:30-23:30 UT (b) EISCAT VHF radar beam 2 power profile data, over the same time interval, as a function of altitude. Pi2 onset times are marked with vertical solid lines and the intervals of HF radar data loss with vertical dashed lines, as in Fig. 2. 


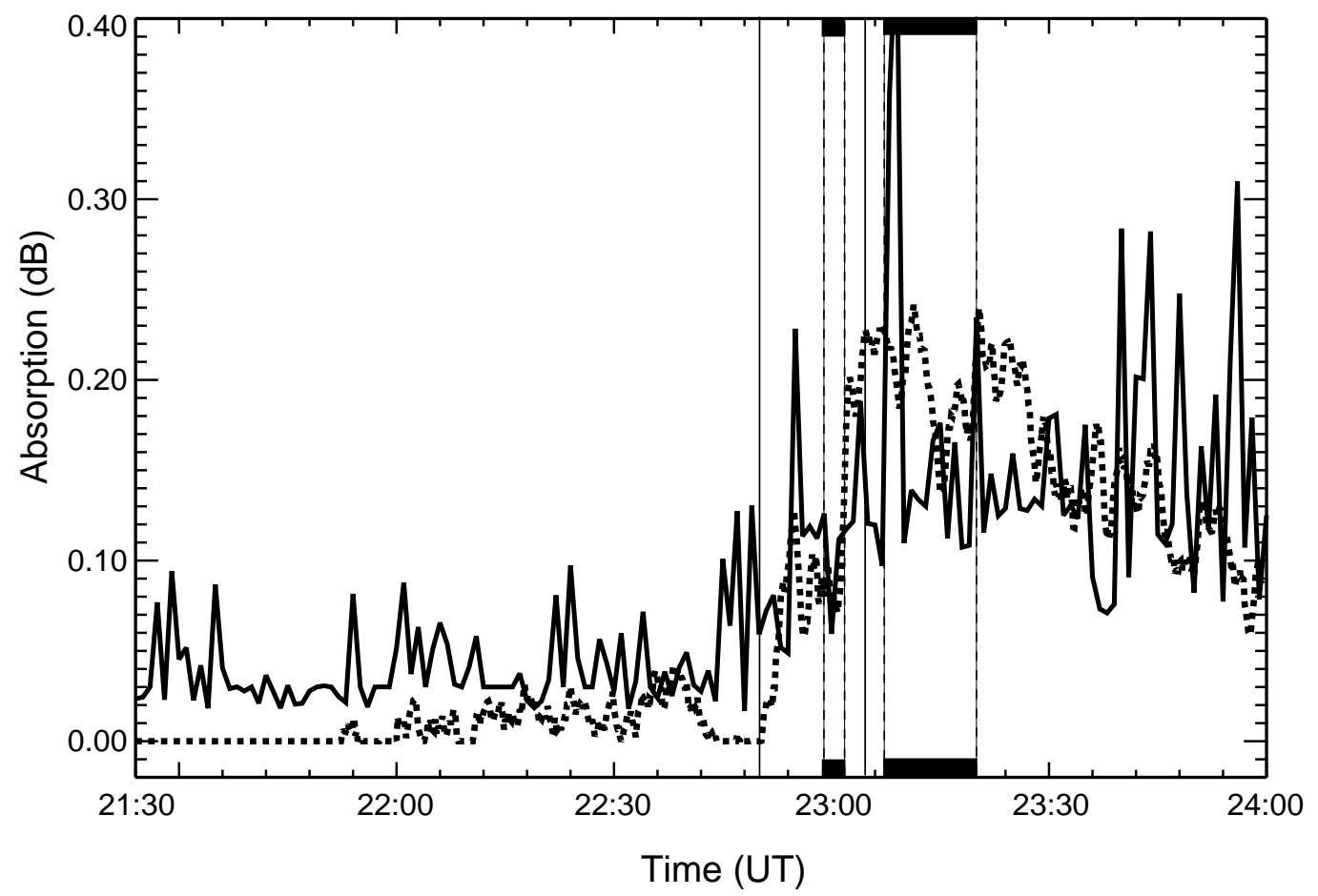

Fig. 5. Measured (dashed line) and modelled (solid line) IRIS beam 2 absorption, between 21:30 and 24:00 UT. See text for details. Pi2 onset times are marked with vertical solid lines and the intervals of HF radar data loss with vertical dashed lines, as in Fig. 2.

\section{Analysis of HF propagation and absorption}

\subsection{Modelling IRIS absorption}

The interval under study here has available both measurements of ionospheric absorption from IRIS, and electron density profiles from EISCAT. The primary focus is to quantify the changes in HF absorption and propagation of the Hankasalmi system using these two data sets; but first, we use the EISCAT VHF beam 2 electron density profiles from the power profile, together with an empirical atmospheric composition and temperature model (MSIS 90), to model the absorption measured by beam 2 of IRIS, which is closest to the EISCAT VHF beam 2. The absorption calculation uses the equation for the absorption coefficient given by Davies (1969), appropriate for a slowly varying plasma and nondeviative propagation

$\kappa=4.6 \cdot 10^{-2}\left[\frac{N v}{\omega^{2}+v^{2}}\right]$,

where $\kappa$, the absorption coefficient is measured in $\mathrm{dB} / \mathrm{km}$, $N$ is the plasma electron density, $\omega$ is the wave angular frequency, and $v$ an effective collision frequency between electrons and all other particles. For radio-wave absorption in the HF or VHF range, the appropriate effective collision frequencies are identical to the standard collision frequencies for momentum transfer (Banks, 1966). Here electron-neutral collision frequencies for $\mathrm{N}_{2}, \mathrm{O}_{2}, \mathrm{O}, \mathrm{H}$, and $\mathrm{He}$ from Schunk and
Nagy (1978) and the electron-ion collision frequency from Banks (1966) have been used in the absorption calculation. The values of neutral density and temperature used in the collision frequency equations are obtained from the MSIS 90 model (Hedin, 1991). The electron-neutral collision frequencies are actually a function of the electron temperature, but here we use the neutral temperature instead, as an approximation. While the electron temperature will exceed the neutral temperature above $120 \mathrm{~km}$, the absorption has typically fallen to $1 \%$ of its peak value at such an altitude (Davies, 1969), so this has a negligible effect on the total calculated absorption.

The absorption coefficient gives the spatial rate of change of absorption, and the total absorption, $A$, (in $\mathrm{dB}$ ) is found, therefore, by integrating the absorption coefficient through distance via a summation, for a ray propagating at an angle $\theta$ to the vertical. Although the calculated absorption assumes straight-line propagation, this does not mean that the rays penetrate the layer at a fixed angle; the Earth's curvature continually changes the effective angle at which the straight-line path passes through an assumed horizontally stratified layer, and this has been included in the calculation, which gives

$$
\begin{gathered}
A(t)=4.6 \cdot 10^{-2} \sum_{g=1}^{g=50}(h(g+1)-h(g))(\sec \theta(h, \text { lat }, \text { lon })) \\
\cdot\left(\frac{N(g, t)_{\mathrm{EISCAT}} v(h, \text { lat }, \text { lon }, t)_{\mathrm{MSIS}}}{\omega^{2}+v^{2}(h, \text { lat }, \text { lon, } t)_{\mathrm{MSIS}}}\right)
\end{gathered}
$$

where $g$ is the EISCAT range gate, $t$ is the time, $h$ is the 

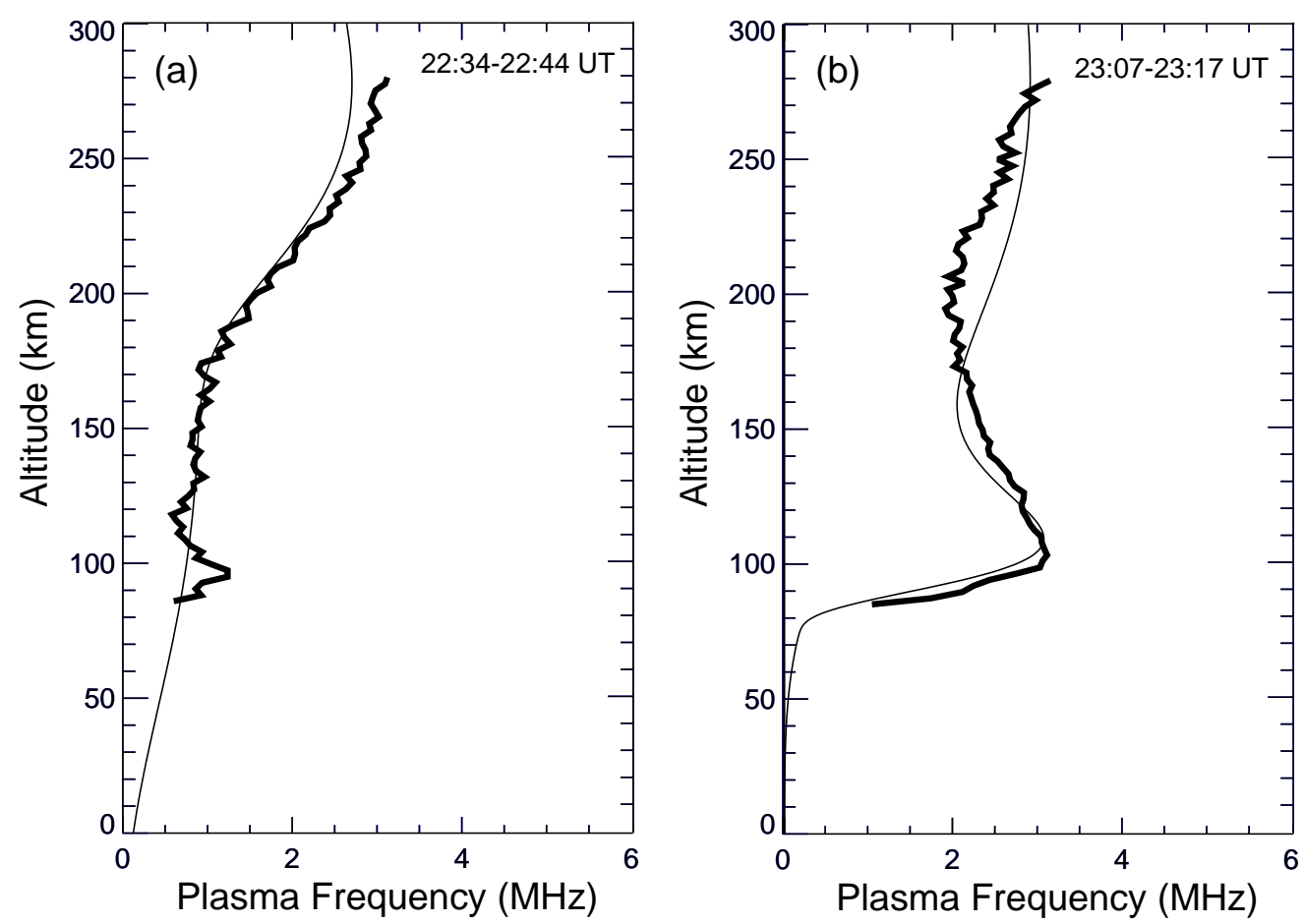

Fig. 6. Ionospheric plasma frequency profiles, derived from the EISCAT VHF beam 2. The data are indicated by the bold lines, and fitted double Chapman layers are indicated by the thin lines. (a) A profile typical of conditions prior to the substorm expansion phase onset (averaged between 22:34 and 22:44 UT). (b) A profile typical of conditions during the expansion phase (averaged between 23:07 and 23:17 UT).

altitude at the start of each range, lat and lon are the latitude and longitude of each gate, $N$ is the electron density measured by EISCAT (a function of range gate and time), $v$ is the total electron collision frequency summed over the individual expressions for each neutral species (where the neutral temperature and density values come from MSIS for each range gate location, and these values are combined with the appropriate EISCAT electron density measurements in the calculation), and $\omega$ is the angular wave frequency of interest. Here we integrate through height (i.e. $\theta=90$ ), since the absorption measured by IRIS has already been normalized through division by the relative path length of the beam. On this occasion, the data quality beam 1 of the EISCAT VHF radar was relatively poor and could not be used for absorption calculations. Beam 2 has an elevation of $30^{\circ}$ and azimuth $359.5^{\circ}$; thus, it does not intersect with any of the IRIS beams in the main absorbing regions of around $80-90 \mathrm{~km}$ altitude. The $90 \mathrm{~km}$ ionospheric intersection of EISCAT actually occurs at a geographic latitude of $70.95^{\circ}$ and a longitude of $19.13^{\circ}$, making the closest beam of IRIS beam 2, which is located some $96 \mathrm{~km}$ to the south of this point. EISCAT has a time resolution of $1 \mathrm{~min}$, and successive altitude gates are separated by $2.25 \mathrm{~km}$. Absorption coefficients are assumed to be constant between each EISCAT range gate. The calculation here also requires that data exist in at least 40 of the first 50 range gates. The calculation is completed at range gate 50 , an altitude of $210 \mathrm{~km}$, as any contributions to the total ab- sorption above this height are negligible.

The results of this calculation are displayed in Fig. 5. The Pi2 onset times are marked with vertical solid lines and the intervals of HF radar data loss with vertical dashed lines, as in Fig. 2. Although the absorption calculation is appropriate for a location significantly poleward of IRIS beam 2, the calculated (Fig. 5, solid line) and measured (Fig. 5, dashed line) absorption show considerable similarity in the overall large-scale features, although small-scale features are not modelled well, due to the structure in the absorption data which is evident in the IRIS data in Figs. 2 and 3. A negligible level of absorption prevails until 22:45 UT, after which the calculated absorption increases steadily until 22:54 UT. Thereafter, the calculated absorption remains enhanced over the pre-substorm levels, but remains small at $\sim 0.2 \mathrm{~dB}$. It shows some signs of decreasing by 24:00 UT. The calculated absorption increases before the measured absorption, which rises at 22:50 UT. This is presumably a consequence of the motion of the substorm-associated absorption, combined with the spatial offset between the EISCAT and IRIS beams. The modest increase in ionospheric absorption measured by IRIS has a large spatial extent, as illustrated in Fig. 3i, and this is supported by a comparison of the calculated absorption with additional beams of IRIS. In fact, even the absorption in the southeast of the IRIS field-of-view, at a distance of $436 \mathrm{~km}$ from EISCAT, is broadly similar to the calculated values. The time of the absorption enhance- 


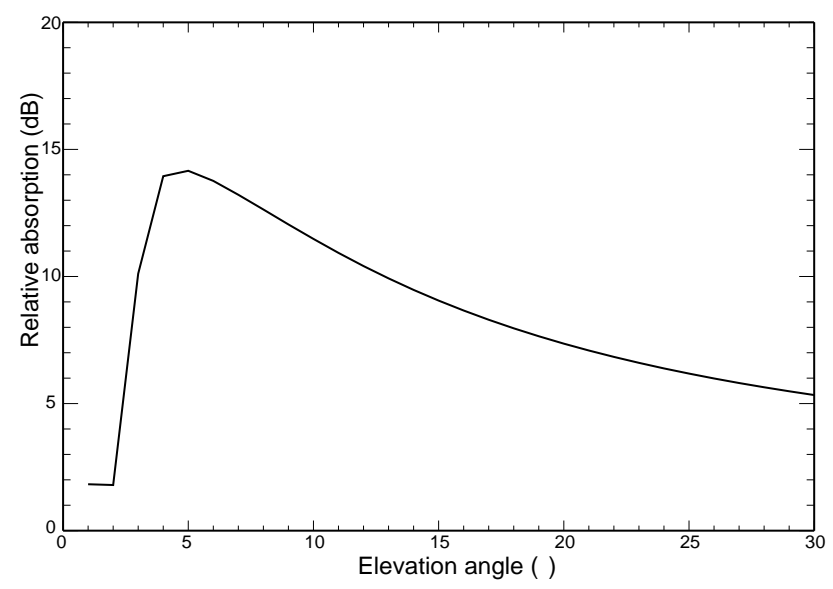

Fig. 7. A calculation of the difference in the expected absorption of the Hankasalmi HF signal before and after the substorm expansion phase onset, as a function of the radar angle-of-arrival. See text for details.

ment to the southeast is slightly delayed with respect to that in Fig. 5, due to the expanding nature of the substorm disturbance, but the level of absorption is of the same order as the calculated values. The similarity between the modelled and measured absorption, and the modest levels of absorption measured throughout the IRIS field-of-view, suggest that the D-region absorption in this case may be approximated as a uniform absorbing region, and it is this assumption upon which the Hankasalmi absorption calculations presented in Sect. 4.2 are based.

\subsection{Modelling Hankasalmi absorption}

Having found a good overall correspondence between modelled and measured values of IRIS absorption, we apply this model to the absorption experienced by the Hankasalmi HF radar. The low EISCAT beam elevation angle means that the ionospheric electron density profiles are not measured at a single location. The resulting 1-D profiles are, however, as useful in the context of analyzing Hankasalmi absorption and HF propagation modes as 1-D profiles measured above a single geographic location; they are used merely to provide an indication of the likely ray absorption and propagation during the substorm interval. Rather than modelling the total absorption for each available point in time, along a fixed elevation angle, as was done for IRIS, we model the total absorption as a function of the radar backscatter elevation angle, using electron density profiles from two specific times, representing the conditions before substorm expansion phase onset and during the main interval of CUTLASS data loss during the substorm expansion phase. Figure $6 \mathrm{a}$ presents the EISCAT VHF beam 2 electron density profiles averaged between 22:34-22:44 UT, a time representative of the profiles from before the substorm-induced absorption enhancement. The profile averaged between 23:07-23:17 UT (Fig. 6b) is representative of the active period, during which the Hankasalmi data were lost. Straight-line propagation is assumed, at a range of elevation angles, using the Hankasalmi operating frequency of $10 \mathrm{MHz}$. The assumption of straight-line propagation is chosen since the vast majority of the total absorption occurs in the D-region and lower E-region, at a point in the ray path where the plasma frequency is not high enough to cause significant refraction of a $10 \mathrm{MHz}$ ray. This assumption also enables a separation of the effects of absorption and changing HF propagation conditions, which will be addressed in Sect. 4.3. The absorption calculation is again based upon Eq. (2), but now with an appropriate value of $\theta$ calculated for each point in the summation. However, the IRIS operating frequency is now replaced by the CUTLASS operating frequency. The absorption calculation has been terminated when the ray reaches the ground range of Troms $\varnothing$ at $69.6^{\circ}$ geographic latitude, a typical range from which backscatter is received during the interval under study. Finally, the total calculated absorption is doubled since, for each ray, the backscattered radiation has passed through the absorbing layer twice (on the outward and backscattered paths).

Rather than calculate the total absorption of the Hankasalmi HF signal, it is most useful to consider the change in absorption brought about by the substorm expansion phase onset. The change in the absorption calculated from the profiles in Figs. 6a and $b$ is presented in Fig. 7. The figure presents the increase in absorption associated with the substorm activity for rays reaching the latitude of Troms $\varnothing$. A different range termination would change the absorption profile calculated, with the range of Troms $\emptyset$ being chosen since it is typical for the data interval under study. Figure 7 illustrates, for a given range, how a low elevation angle path has a lower increase in absorption due to the substorm, since it propagates predominantly at an altitude lower than the main absorbing region, rather than within it. The peak increase in absorption on the propagation path to Troms $\varnothing$ is just over $14 \mathrm{~dB}$ at an elevation angle of $5^{\circ}$, with increases being smaller than $10 \mathrm{~dB}$ for elevation angles either greater than $15^{\circ}$ or less than $3^{\circ}$. This level of absorption would suggest a drop in received power of at most $14 \mathrm{~dB}$ across the entire region in which the signal was being received, thereby resulting, in certain regions, in a complete loss of the signal. In fact, the Hankasalmi backscattered power data presented in Figs. 3 and 4 demonstrate that some regions of the field-of-view showed the complete loss of a $30 \mathrm{~dB}$ signal, while neighbouring regions witnessed either little or no power reduction, or even in some places, an increase. This lack of consistency between prediction and observation suggests that in this case, absorption is not the primary explanation for the HF radar signal loss.

\subsection{Modelling Hankasalmi HF propagation}

The EISCAT estimated electron density profiles displayed in Fig. 6 are again used as representative plasma frequency profiles prior to and during the substorm expansion phase. A ray-tracing simulation has been undertaken, using the code 

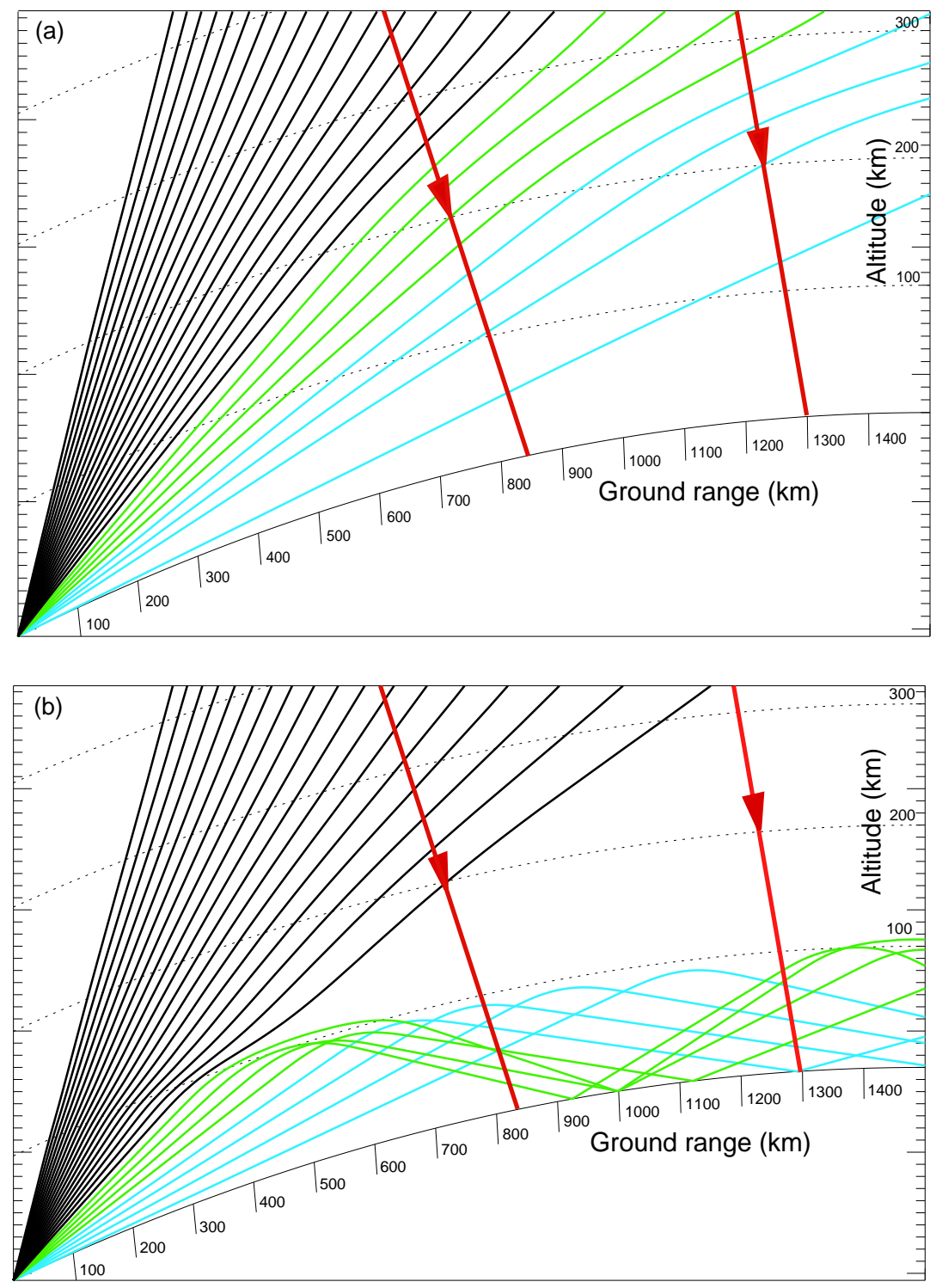

Fig. 8. A ray-tracing simulation of the HF propagation conditions for Hankasalmi (a) prior to the substorm expansion phase onset (based upon the ionospheric profile in Fig. 6a) and (b) during the substorm expansion phase (based upon the ionospheric profile in Fig. 6b). The geomagnetic field direction is indicated by the red lines. The changing HF propagation conditions affecting the HF rays indicated in black, blue and green are discussed in the text.

developed by Jones and Stephenson (1975). The ray-tracing program has been used to model radio-wave propagation at $10 \mathrm{MHz}$, the operating frequency of the CUTLASS Hankasalmi radar, through plasma frequency profiles provided by functional fits found for the profiles measured between 22:34-22:44 UT and 23:07-23:17 UT. The form used for the fitting is the sum of two Chapman layers with the six model parameters adjusted to give the best fit. These functional fits are also shown in Figs. 6a and b. Ray trace calculations through the profiles in Figs. $6 \mathrm{a}$ and $\mathrm{b}$ are displayed in Figs. 8a and b, respectively. The rays are plotted in elevation angle steps of $2^{\circ}$, and range between $0^{\circ}$ and $50^{\circ}$. The HF propagation is thus expected to evolve from that in Fig. 8a to that in Fig. 8b, between 22:34 and 23:17 UT. In Fig. 8a, prior to the substorm expansion phase onset, little evidence for significant refraction of the HF rays is observed in the first $1500 \mathrm{~km}$ of the radar field-of-view. A consideration of the relative orientation of the HF rays and the geomagnetic field, represented by two red arrows in Fig. 8a, demonstrates that a wide range of elevation angles lie close to the fieldorthogonal condition, which is a prerequisite for backscatter, and may provide backscatter if suitable ionospheric irregularities exist. By contrast, Fig. 8b, representative of conditions during the substorm expansion phase, shows very significant HF refraction for some values of elevation angle. Rays above $16^{\circ}$ elevation (coloured black in Figs. 8a and b) are 
not strongly refracted (or indeed, absorbed) by the substormenhanced precipitation. In contrast, rays with elevation in the ranges $8^{\circ}-14^{\circ}$ (coloured green in Figs. $8 \mathrm{a}$ and $\mathrm{b}$ ) are strongly refracted in Fig. 8b, and cease to be candidates for orthogonal F-region backscatter after the substorm expansion phase onset, except at low values of ground range $(\sim 500 \mathrm{~km})$, where E-region backscatter may, in fact, be most likely. Lower elevation angle rays (coloured blue in Figs. 8a and b) are similarly refracted, but the refraction process opens up a new HF propagation path which may sustain backscatter, with orthogonality being achieved at ranges $800-1200 \mathrm{~km}$. The rays coloured green and blue in Fig. 8 might be expected to provide ground scatter in the Hankasalmi data after the substorm onset. However, ionospheric scatter is expected from the same ranges, and only the scatter of the highest power will be detected. Any ground scatter will be attenuated by the requirement for the HF ray to pass through the absorbing Dregion 4 times. Examination of the backscatter in Fig. 2 does reveal that some ground scatter is identified, intermingled with the dominant ionospheric scatter. This suggests that the ground scatter is of higher power than the ionospheric scatter in only a few range gates.

\section{Discussion}

Ionospheric radar and riometer data, combined with HF absorption and propagation modelling, has been presented for an isolated substorm occurring over Scandinavia on $21 \mathrm{Au}-$ gust 1998. Detailed observations of this substorm have been presented by Yeoman et al. (2000), and mid-latitude Pi2 observations indicated that the substorm expansion phase onset commenced at 22:50 UT, with a further intensification at 23:05 UT (Fig. 2). The EISCAT VHF radar detected the enhanced particle precipitation associated with the expansion phase onset and intensification at 22:55 and 23:04 UT, while almost simultaneously two intervals of data loss were recorded by the Hankasalmi radar, between $69^{\circ}-74^{\circ}$ geomagnetic latitude, at 22:59-23:02 UT and 23:07-23:21 UT, respectively, (Fig. 4). Such intervals of HF radar data loss are generally interpreted as resulting from HF absorption (Milan et al., 1996).

The effect of HF absorption on the Hankasalmi radar system has been addressed via a modelling calculation based upon the electron density from the power profile measured by the EISCAT VHF radar and accepted electron-neutral and electron-ion collision frequencies derived using the MSIS model. A comparison of the absorption calculated for IRIS, and the measured IRIS absorption at $38.2 \mathrm{MHz}$ has demonstrated that the absorbing layer was large scale, and that a reasonable agreement was achieved between the measured and calculated values. Applying the same calculation, but this time to the Hankasalmi radar, operating at $10 \mathrm{MHz}$, has revealed that the substorm-associated precipitation is expected to produce a maximum absorption increase of $\sim 15 \mathrm{~dB}$, at a radar elevation angle of $5^{\circ}$. An examination of the measured changes in Hankasalmi backscatter power, in contrast, reveals a more variable picture, with a loss of backscatter of $30 \mathrm{~dB}$ or greater in some parts of the field-of-view, while elsewhere very little power is lost (Fig. 3). Therefore, it is clear that HF absorption alone is insufficient to explain the behaviour of the HF radar data during the substorm expansion phase.

The ray traces through the ionospheric electron density profiles before and after the substorm expansion phase onset presented in Fig. 8 suggest a significant alteration in HF propagation conditions. For elevation angles over $20^{\circ}$ the two ray traces are very similar, showing quasi-linear propagation, which penetrates the ionosphere. Many of these rays are viable candidates for F-region backscatter. The most obvious difference between the ray traces is that during pre-substorm onset, all the rays eventually penetrate the ionosphere, whereas during post-substorm onset, the rays of elevation angles of less than $16^{\circ}$ are reflected earthward. Such earthward-reflected rays will be far from satisfying the magnetic field orthogonality condition required for backscatter over much of their propagation path, and, therefore, are not candidates for producing backscatter from these regions, whereas most of the rays which are not reflected will undergo field orthogonal propagation at some point along their path. Clearly, a change in propagation conditions such as this will result in alterations to the power distribution of the backscatter. Figure 8b suggests that after the substorm expansion phase onset there will be an absence of radar returns of elevation angles less than about $16^{\circ}$ beyond a ground range of $\sim 600 \mathrm{~km}$, with the possible exception of a very low elevation angle mode in the range $800 \mathrm{~km}$ to $1200 \mathrm{~km}$. Thus, the ray-tracing calculation may offer an explanation for the changes in Hankasalmi's performance during the substorm. This prediction from the ray-tracing calculation may be tested directly by an examination of the radar angle-ofarrival information. The occurrence of such elevation angle data from each scan, beam and range gate, is presented in the form of a contour map as a function of range and elevation angle in Fig. 9. The $30 \mathrm{~min}$ preceding the substorm expansion phase onset (22:20-22:50 UT) is displayed in Fig. 9a and the $30 \mathrm{~min}$ following the onset (22:50-23:20 UT) is displaced in Fig. 9b. Figure 9a shows a high occurrence frequency across a broad range of angles between approximately $5^{\circ}$ and $30^{\circ}$, and ranges mainly over $800 \mathrm{~km}$, although there is also a thin strip of data from about $400 \mathrm{~km}$, which probably results from E-region backscatter. This is consistent with the fairly uniform HF propagation predicted in Fig. 8a. In Fig. 9b, by contrast, occurrences of between $8^{\circ}$ and $17^{\circ}$ are strongly reduced, corresponding to the rays which were deflected from locations where they could potentially provide radar backscatter (those rays colour-coded green in Fig. 8). In addition, a new, low elevation angle mode $\left(<8^{\circ}\right)$ has appeared between the ranges of $500-700 \mathrm{~km}$, and $1200-1400 \mathrm{~km}$. These rays are those colour-coded blue in Fig. 8. Therefore, it appears that those rays at very low elevations, which achieve orthogonality near $1000 \mathrm{~km}$ range, and the rays with slightly higher elevation angles, which achieve orthogonality near their reflection point at $500 \mathrm{~km}$ range in 
(a)

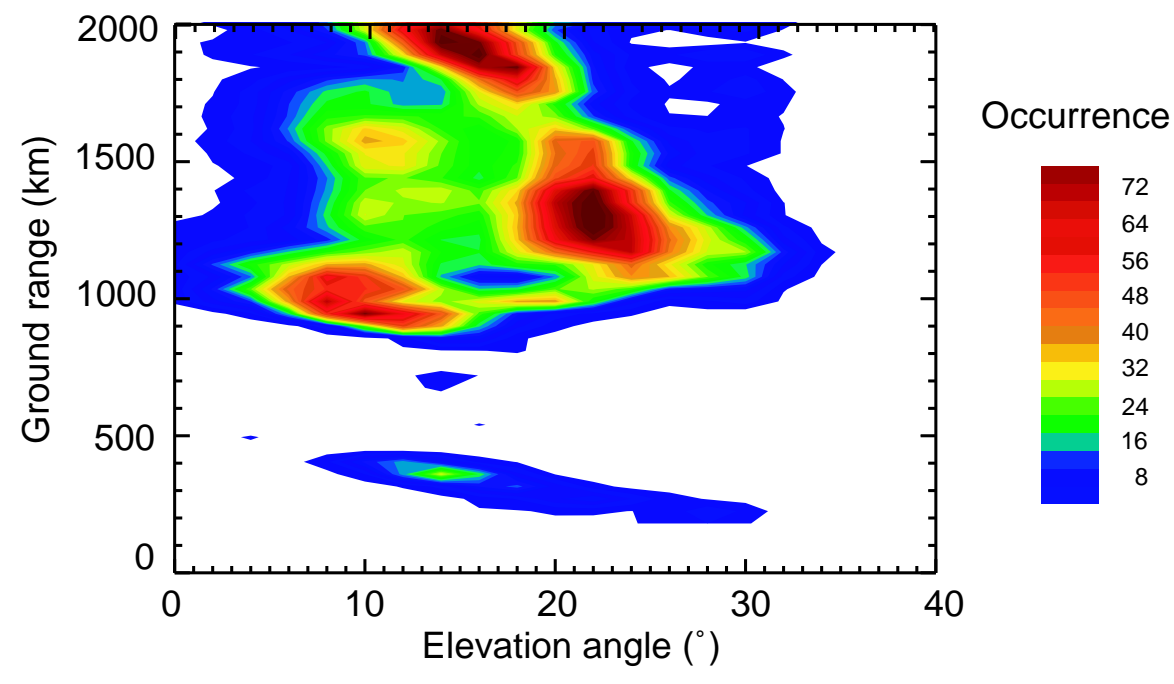

(b)

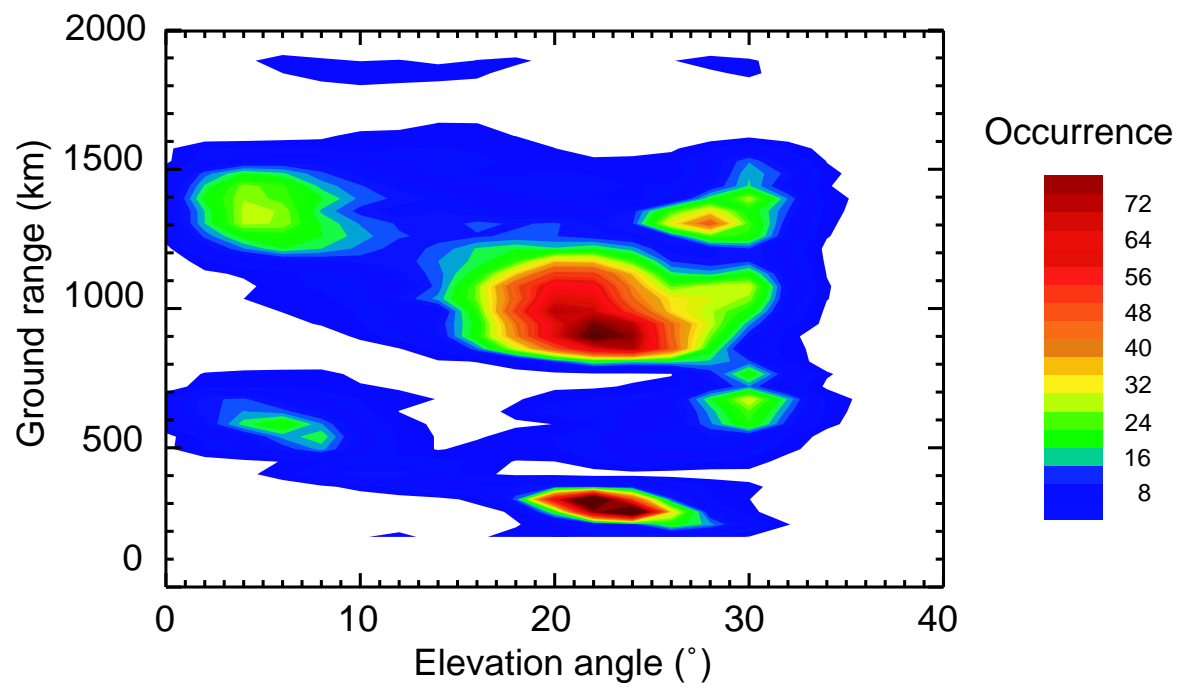

Fig. 9. The occurrence of measured Hankasalmi radar angle-of-arrival information as a function of ground range. Angle-of-arrival information from all beams of Hankasalmi are used. (a) The interval 22:20-22:50 UT, before the substorm expansion phase onset (b) The interval 22:50-23:20 UT, during the substorm expansion phase.

Fig. $8 \mathrm{~b}$, are both viable new propagation paths for HF radar backscatter. The total amount of backscatter recorded is also clearly reduced between Figs. 9a and b. These changes in received backscatter elevation angles are largely consistent with the ray-tracing analysis presented in Fig. 8. This suggests that the changes in, and losses of, backscatter at substorm onset were primarily a consequence of altered HF propagation conditions. The substorm precipitation resulted in a region of modest absorption increase of a scale size similar to the IRIS field-of-view. HF propagation conditions in this region were significantly altered, with a new, low elevation angle propagation path opening up in the region of the substorm-affected ionosphere.
One aspect of the Hankasalmi radar data not explained by the analysis above is why the Hankasalmi radar data show two distinct intervals of data loss, one very soon after the onset of the substorm at 22:50 UT (occurring from 22:5923:02 UT on Hankasalmi beam 9 in Fig. 2), and one just after the substorm intensification at 23:05 UT (occurring from 23:07-23:21 UT). The first short-lived interval of data loss occurred when the first very low levels of enhanced absorption were observed by IRIS, but they preceded the time when the measured and calculated IRIS absorption reached a peak (Fig. 5), and thus, before the changes in HF propagation had reached their full extent. This initial interval of Hankasalmi data loss follows an interval of suppressed flow ve- 


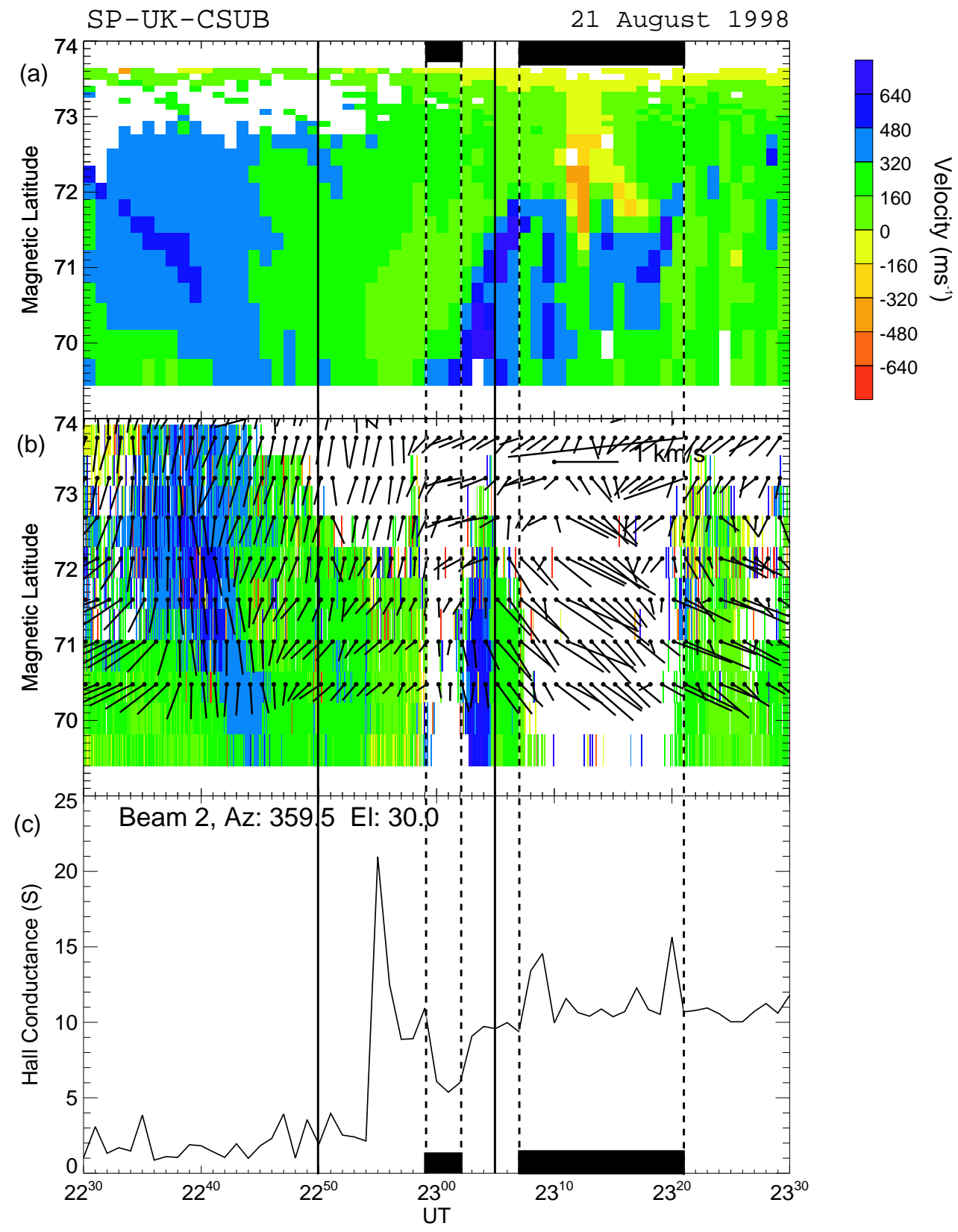

Fig. 10. (a) Line-of-sight velocity measurements from the ESR, as a function of magnetic latitude, for the interval 22:30-23:30 UT. Pi2 onset times are marked with vertical solid lines and the intervals of HF radar data loss with vertical dashed lines, as in Fig. 2. (b) Hankasalmi beam 9 measurements of line-of-sight velocity for the same times and latitudes as panel (a). Overlayed are estimates of the convection velocity, derived from a beam-swinging analysis of data from beams 1 and 2 of the EISCAT VHF system. (c) An estimate of the Hall conductance derived from data measured in the beam 2 direction of the EISCAT VHF system.

locities, visible in the Hankasalmi line of sight data presented in Figs. 2 and 10 after 22:55 UT. Clearly, as Hankasalmi suffers from data loss shortly after this time, it is not an ideal instrument to characterize the velocity field. However, the EISCAT radars do not suffer from such a data loss, and can provide independent velocity measurements where the EISCAT beams are close to being collocated with Hankasalmi beam 9. Both the EISCAT VHF Troms $\varnothing$ radar and the EIS-
CAT Svalbard radar (ESR) have provided F-region plasma velocities during the SP-UK-CSUB routine (Davies et al., 2000). The Troms $\varnothing$ split beams have been used for beamswinging, in order to estimate 2-D plasma velocities in the vicinity of CUTLASS beam 9, while the ESR was pointing directly down CUTLASS beam 9, the configuration depicted in Fig. 1. Figure 10a presents line-of-sight velocity from the ESR, while Fig. 10b presents Hankasalmi beam 9 data over- 
laid with velocity vectors derived from the VHF beams 1 and 2, calculated via a beam-swinging technique. Finally, Fig. 10c presents the Hall conductance derived from the VHF beam 2 power profile equatorward of the velocity measurements. The Pi2 onset times are marked with vertical solid lines and the intervals of HF radar data loss with vertical dashed lines, as in Fig. 2. An increase in energetic particle precipitation, as evidenced from the enhanced Hall conductance, peaks at 22:55 UT, and persists at a lower, but still enhanced level thereafter. The initial Hankasalmi data loss interval can be seen to coincide with an interval of reduced ionospheric convection velocity, whereas the convection is strong for the second interval, in spite of the conductivity increase. A possible consequence of such an electric field suppression is the reduction of ionospheric irregularities in the low electric field region (Milan et al., 1999). The increasing strength of the equatorward flows at 23:02 UT indicate the return of the Hankasalmi data. Subsequent to this feature an extended data gap appears in the Hankasalmi data, after the electric field has recovered, but also after the substorm precipitation has significantly altered the HF propagation conditions. The likelihood that irregularities would have been lost during the substorm interval due to reduced electric fields has so far been neglected, and of course, the level of scattering structure present at any particular time and place cannot be easily assessed. The best evidence that one can obtain simply in support of there being an effective depletion in scattering structure is to show that the electric field strength and radar power have been reduced simultaneously in a particular location. This is the case in Fig. 10, and suggests that electric field reduction plays some role in the initial, short-lived interval of HF radar data loss.

\section{Summary}

Data from the Hankasalmi HF radar, the EISCAT incoherent scatter radars and the IRIS riometer, combined with calculations of HF absorption and propagation have enabled a quantitative insight to be gained into the operational constraints put upon HF radar systems by changes in the ionosphere associated with substorm precipitation. While large substorm expansion phase onsets local to the radar field-ofview would result no doubt in the complete absorption of the SuperDARN HF radar signal, we have demonstrated that for smaller events the radars are able to receive backscatter in spite of riometer absorption levels of $\sim 0.5 \mathrm{~dB}$ at $38 \mathrm{MHz}$. A more significant constraint is presented by the changing HF propagation conditions, which can result in the loss of viability of HF rays of certain elevation angles as candidates for HF backscatter. In contrast, new, very low elevation angle backscatter HF propagation paths are opened up by the substorm precipitation. SuperDARN radars are frequency agile between 8 and $20 \mathrm{MHz}$, so careful frequency management, when combined with ray-tracing simulations such as that presented in Fig. 8, may significantly improve data coverage during the substorm expansion phase. In addition, the
HF radar data loss may be used to track the location and propagation of the enhanced regions of D-region absorption, and to evaluate the modifications to the available HF propagation paths which are imposed on HF communications links by the localized regions of the auroral ionosphere affected by substorm precipitation. In addition, it is suggested that for brief intervals during the substorm expansion phase that the suppression of the ionospheric electric field can contribute to the loss of HF radar backscatter, via a reduction in the ionospheric irregularities responsible for forming the radar targets.

Acknowledgements. The CUTLASS HF radars are deployed and operated by the University of Leicester, and are jointly funded by the UK Particle Physics and Astronomy Research Council (Grant no. PPA/R/R/1997/00256), the Finnish Meteorological Institute, and the Swedish Institute for Space Physics. The authors thank the director and staff of EISCAT for the operation of the facility and dissemination of the data. EISCAT is an international facility funded collaboratively by the research councils of Finland (SA), France (CNRS), the Federal Republic of Germany (MPG), Japan (NIPR), Norway (NAVF), Sweden (NFR) and the United Kingdom (PPARC). IMAGE data were kindly supplied by the Finnish Meteorological Institute. JKG was supported by a PPARC studentship. JAD is supported on PPARC Grant number PPA/G/O/1997/000254. The riometer data originated from the Imaging Riometer for Ionospheric Studies (IRIS), operated by the Department of Communications Systems at Lancaster University (UK), funded by the Particle Physics and Astronomy Research Council (PPARC) in collaboration with the Sodankylä Geophysical Observatory.

The Editor in chief thanks G. Chisham for his help in evaluating this paper.

\section{References}

Baker, K. B., and Wing, S.: A new magnetic coordinate system for conjugate studies at high-latitudes, J. Geophys. Res., 94, 91399143, 1989.

Banks, P. M.: Collision frequency and energy transfer: Ions, Planet. Space Sci. 14, 1105-1122, 1966.

Baumjohann, W., Pellinen, R. J., Opgenoorth, H. J., and Nielsen, E.: Joint two-dimensional observations of ground magnetic and ionospheric electric fields associated with auroral zone currents: current systems associated with local auroral break-ups, Planet. Space. Sci., 29, 431-447, 1981.

Browne, S., Hargreaves, J. K., and Honary, F.: An imaging riometer for ionospheric studies, Electronics and Communication Engineering Journal 7, 209-217, 1995.

Davies, J. A., Yeoman, T. K., Lester, M., and Milan, S. E.: A comparison of F-region ion velocity observations from the EISCAT Svalbard and VHF radars with irregularity drift velocity measurements from the CUTLASS Finland HF radar, Ann. Geophysicae, 18, 589-594, 2000.

Davies, K.: Ionospheric Radio, Blaisdell Publishing Company, USA, 1969.

Greenwald, R. A., Baker, K. B., Dudeney, J. R., Pinnock, M., Jones, T. B., Thomas, E. C., Villain, J.-P., Cerisier, J.-C., Senior, C., Hanuise, C., Hunsucker, R. D., Sofko, G., Koehler, J., Nielsen, E., Pellinen, R., Walker, A. D. M., Sato, N., and Yamagishi, H.: 
Darn/Superdarn: A global view of the dynamics of high-latitude convection, Space Sci. Rev., 71, 761-796, 1995.

Hedin, A. E.: Extension of the MSIS thermosphere model into the middle and lower atmosphere, J. Geophys. Res. 96, 1159-1172, 1991.

Inhester, B., Baumjohann, W., Greenwald, R. A., and Nielsen, E.: Joint two-dimensional observations of ground magnetic and ionospheric electric fields associated with auroral zone currents 3. Auroral zone currents during the passage of a westward travelling surge, J. Geophys., 49, 155-162, 1981.

Jones, R. M. and Stephenson, J. J.: A versatile three-dimensional ray-tracing computer program for radio waves in the ionosphere, OT Report 75-76, US Govt. Printing Office, Washington DC, 1975.

Lester, M., Milan, S. E., Besser, V., and Smith, R.: A case study of HF radar spectra and $630.0 \mathrm{~nm}$ auroral emission in the premidnight sector, Ann. Geophysicae, 19, 327-339, 2001.

Lewis, R. V., Freeman, M. P., and Reeves, G. D.: The relationship of HF radar backscatter to the accumulation of open magnetic flux prior to substorm onset, J. Geophys. Res., 103, 26613-26619, 1998.

Lewis, R. V., Freeman, M. P., Rodger, A. S., Reeves, G. D., and Milling, D. K.: The electric field response to the growth phase and expansion phase onset of a small isolated substorm, Ann. Geophysicae, 15, 289-299, 1997.

Lühr, H.: The IMAGE magnetometer network, STEP International Newsletter, 4, no. 10, 4-6, 1994.

Milan, S. E., Davies, J. A., and Lester, M.: Coherent HF radar backscatter characteristics associated with auroral forms identified by incoherent radar techniques: a comparison of CUTLASS and EISCAT observations, J. Geophys. Res., 104, 22 591-22 604, 1999.

Milan, S. E., Jones, T. B., Lester, M., Warrington, E. M., and Reeves, G. D.: Substorm correlated absorption on a $3200 \mathrm{~km}$ trans-auroral HF propagation path, Ann. Geophys., 14, 182-190, 1996.

Morelli, J. P., Bunting, R. J., Cowley, S. W. H., Farrugia, C. J., Freeman, M. P., Friis-Christensen, E., Jones, G. O. L., Lester, M., Lewis, R. V., Lühr, H., Orr, D., Pinnock, M., Reeves, G. D., Williams P. J. S., and Yeoman, T. K.: Radar observations of auroral zone flows during a multiple-onset substorm, Ann.Geophysicae, 13, 1144-1163, 1995.
Opgenoorth, H. J., Bromage, B., Fontaine, D., LaHoz, C., Huuskonen, A., Kohl, H., Løvhaug, U.-P., Wannberg, G., Gustaffson, G., Murphree, J. S., Eliasson, L., Marklund, G., Potemra, T. A., Kirkwood, S., Nielsen, E., and Wahlund, J.-E. Coordinated observations with EISCAT and the Viking satellite: the decay of a westward travelling surge, Ann. Geophyicae, 7, 479-500, 1989.

Rishbeth, H. and Williams, P. J. S.: The EISCAT ionospheric radar: The system and its early results Q. J. R. Astr. Soc., 26, 478-512, 1985.

Robinson, T. R.: Towards a self-consistent nonlinear theory of radar-auroral backscatter, J. Atmos. Terr. Phys., 48, 417-422, 1986.

Schunk, R. W. and Nagy, A. F.: Electron temperatures in the Fregion of the ionosphere: Theory and observations, Rev. Geophys. Space Phys. 16, 355-399, 1978.

Shand, B. A., Yeoman, T. K., Lewis, R. V., Greenwald, R. A., and Hairston, M. R.: Inter-hemispheric contrasts in the ionospheric convection response to changes in the Interplanetary Magnetic Field and substorm activity: A case study, Ann. Geophysicae, 16, 764-774, 1998.

Wannberg G., Wolf, L., Vanhainen, L.-G., Koskenniemi, K., Röttger, J., Postila, M., Markkanen, J., Jacobsen, R., Stenberg, A., Larsen, R., Eliassen, S., Heck S., and Huuskonen, A.: The EISCAT Svalbard radar: a case study in modern incoherent scatter radar system design, Radio Science, 32, 2283-2307, 1997.

Yeoman, T. K. and Lühr, H.: CUTLASS/IMAGE observations of high-latitude convection features during substorms, Ann. Geophysicae, 15, 692-702, 1997.

Yeoman, T. K., Davies, J. A., Wade, N. M., Provan, G., and Milan, S. E.: Combined CUTLASS, EISCAT and ESR observations of ionospheric plasma flows at the onset of an isolated substorm, Ann. Geophysicae, 18, 1073-1087, 2000.

Yeoman, T. K., Lewis, R. V., Milan, S. E., and Watanabe, M.: An interhemispheric study of the ground magnetic and ionospheric electric fields during the substorm growth phase and expansion phase onset, J. Geophys. Res., 104, 14 867-14 877, 1999.

Yeoman, T. K., Mukai, T., and Yamamoto, T.: Simultaneous Ionospheric and Magnetospheric Observations of Azimuthally Propagating Transient Features During Substorms, Ann. Geophysicae, 16, 754-763, 1998. 